\title{
Supramolecular complex formation in cell signaling and disease: an update on a recurrent theme in cell life and death
}

\author{
LISETTE LEYTON ${ }^{1}$ and ANDREW F.G.QUEST ${ }^{2}$
}

\author{
${ }^{1}$ Program of Morphology and ${ }^{2}$ Program of Cellular and Molecular Biology; \\ ${ }^{1}$ and ${ }^{2}$ Laboratory of Cellular Communications, FONDAP Center for Molecular studies of the Cell (CEMC)- \\ ICBM (Instituto de Ciencias Biomédicas)-Faculty of Medicine, University of Chile.
}

Cells are constantly exposed to a multitude of environmental cues. In order to respond appropriately to a given stimulus, integrated analysis of the provided information is required. To this end, signal transduction pathways, the cellular communication highways responsible for linking external cues via receptors to changes in cell cytosol and nucleus, must be cross-linked in a network. In the jargon of signal transduction, this process is referred to as "cross-talk" between signaling pathways. Inherent to this process is the ability of individual elements to interact not only with components of the same pathway but also those from different ones. At the molecular level, the importance of this aspect to signaling is perhaps best underscored by the existence of so-called scaffolding proteins, which, in the absence of enzymatic activity, function by linking multiple proteins from the same or different pathways. Hence, alterations in cellular behavior may be viewed as the consequence of a multitude of protein-protein, proteinlipid and protein-DNA interactions associated with signaling.

Today, the secrets of signal transduction are being unraveled at a steadily increasing pace thanks to the availability of genome sequences from various species, including humans. Perhaps, one important insight from the analysis of such data is that proteins are modular by nature. Although the existence of specific protein modules was well accepted prior to the advent of genome sequencing, the sheer magnitude now apparent was unexpected. Furthermore, given that genome size clearly does not reflect the functional complexity of an organism, some speculate that this characteristic may be more faithfully encrypted in modularity of the resulting proteins (Lawler, 2003).

Some years ago, the question was raised as to why proteins are so large (Srere, 1984). This enigma has now been solved rather elegantly: protein domains responsible for enzymatic activity are combined with modules responsible for correct spatial and temporal regulation of protein localization. Furthermore, functional analysis has revealed that these traits -activity and positional informationare crucial for correct protein function. Most intriguingly, many experiments can now be designed more rationally thanks to guidance provided by computerized analysis of the wealth of information available in different sequence databases. Currently, enormous resources are being invested in an attempt to combine genetics, molecular and cellular biology, medicine as well as biochemistry to understand not only 
cellular composition, but also how individual components are connected and how this complex network of proteins may be manipulated to improve human health care (Lawler, 2003). Thus, we may anticipate that scientific discoveries in the area of cellular signaling will contribute, in a very significant way, to converting the information encrypted by genes into cures for diseases.

With such aspects in mind, an international symposium entitled "Supramolecular Complex Formation in Signaling and Disease" brought together several internationally-renowned researchers and a total of 100 symposium participants in Santiago, Chile, to discuss the latest findings in selected areas of cell signaling. Some of the ideas discussed on that occasion in September 2002 are summarized in a special edition of Biological Research (Biol. Res. 35(2) 2002). An introductory article provides a "road map" to the event (Leyton and Quest, 2002). One and a half years later, this paper will review briefly progress made since then in selected areas of signal transduction related to specification of cell fate during development, changes in cell morphology, immunological responses, calcium signaling and cell death.

\section{Signaling associated with cell fate specification during development}

The identification of genes involved in organogenesis during development and the signaling pathways implicated require somewhat different approaches to those generally used. Ongoing research takes advantage of existing databases to identify genes first and then performs anti-sense knockdown experiments to rapidly assess gene function. Looking into the future, we may anticipate embryological manipulation of different organisms to reveal the source and nature of molecules specifying cell fate and differentiation. For example, in the induction of the neural crest in Brachydanio rerio (zebra fish), Notch/Delta signaling has been the focus of recent attention. However, given the wealth of sequencing data already available for this system (http:/
/www.sanger.ac.uk/Projects/D_rerio/), it would not be surprising that many more genes will be identified in the near future.

For Xenopus laevis, induction of the neural crest at the boundary between the neural plate and epidermis involves a complex genetic program that includes a number of transcription factors (reviewed in Aybar, et al., 2002). The best-characterized transcription factors of the neural fold are the zinc finger proteins Xsnail and Xslug. Both are members of the Snail superfamily that regulate development of the neural crest once activated downstream of Notch. Upon ligand binding, Notch receptors are proteolytically cleaved to yield a cytoplasmic fragment that translocates to the nucleus where it associates with DNAbinding proteins to form a complex that facilitates activation of transcription (reviewed in Mumm and Kopan, 2000; Haines and Irvine, 2003).

Recently, Mayor and co-workers have reported that the transcription factors Snail and Slug are functionally equivalent; however, Snail is able to induce Slug expression and is required for neural crest specification and migration (Aybar, et al., 2003). Additionally, Snail, but not Slug, was also shown to control expression of Sox 10, another transcription factor involved in development of embryonic tissues which may lie between Snail and Slug in the sequence controlling neural crest development (Aybar and Mayor, 2002; Honore, et al., 2003). Hence, Notch signaling involves the formation of complexes between proteins and DNA that are important in governing cell fate.

Besides Notch, other molecules have also been implicated in determining cell fate. Although in principle any diffusible molecule could be employed in a gradient to define cell functions, the repertoire of signals that cells actually use for communication in development is limited to a few highly-conserved families of signaling proteins. Among these, fibroblast growth factor (FGF) and Wnt ligands, which interact with tyrosine kinase and heptahelicoidal receptors, respectively, are both important in animal development. Wnt signaling is crucially implicated in the 
development of organs and tissues in multicellular organisms, and many of the genes regulated by this signaling pathway are transcription factors. The expression of Sox 10, for example, has been shown to be dependent on FGF and Wnt activity (Honore, et al., 2003).

At least four different pathways emerge from Wnt when interacting with its receptor (Frizzled), including the Canonical Wnt pathway, the planar cell polarity pathway, the spindle orientation and asymmetric cell division pathway, and the $\mathrm{Wnt} / \mathrm{Ca}^{2+}$ pathway (reviewed in Hendriks and Reichmann, 2002). What determines whether signaling occurs via one or the other cascade is still a matter of intense research. However, it is known, for example, that cell movements during Xenopus gastrulation are determined by the planar cell polarity pathway. Activation in parallel of both the Rac/Jun-N-terminalkinase (JNK) and Rho/Rho kinase (ROCK) pathways provides an additional stimulus for many cytoskeletal changes necessary for this process to occur. However, activation of small $\mathrm{G}$ proteins in Xenopus gastrulation is thought to be independent of the canonical Wnt signaling pathway (Habas, et al., 2003). Thus, determination of the appropriate signaling pathway is probably linked to spatio-temporal expression of the molecules involved.

Differentiation is an important process during both development and adult life. In both situations, stem cells give rise to different cell types or tissues depending on the cues provided by the surrounding environment. Stem cells are multipotent, self-renewing cells that can either generate a daughter cell of equivalent proliferative capacity or a phenotypically-different cell with lower proliferative capacity. Similarities are apparent in cancer cells, prompting the idea that stem cells may also be important in this disease. In this respect, the best example is provided by teratocarcinomas where development of very different kinds of cells starting from limited number of equivalent progenitors is observed. Therefore, cancer stem cells have the ability to proliferate and differentiate but do so in a poorly-controlled fashion and hence cannot be considered normal (reviewed in Pardal, et al., 2003).

An emerging question is whether overexpression of ligands that promote normal stem self-renewal, such as Wnt or Notch may promote neoplastic proliferation of such cells. Indeed, Wnt not only plays an important role in embryogenesis, but also is important in carcinogenesis, since increased levels are associated with the development of various cancers (Kirikoshi and Katoh, 2002; Katoh, 2003). Likewise, overexpression of intact Notch receptors has also been reported in a number of carcinomas (Suzuki, et al., 2000; Weijzen, et al., 2003).

Beta-catenin is an important component of the canonical Wnt pathway that is released from a multiprotein complex by Wnt signaling and transported to the nucleus where it activates the transcription of several genes when associated with the $\mathrm{T}$ cell factor (TCF). In the absence of Wnt signaling, b-catenin is phosphorylated, ubiquitinated and degraded via the proteasome pathway. Alternatively, $\beta$ catenin is also associated with cadherin receptors and such binding precludes interaction with TCF (reviewed in Hendriks and Reichmann, 2002). Hence, inclusion of $\beta$-catenin, into different types of complexes determines both life span and signaling function of this protein (Simcha, et al., 2001).

Alternatively, precisely because Wnt promotes proliferation of somatic adult stem cells, it may also be potentially useful in tissue engineering. For example, expansion and self-renewal of hematopoietic progenitors and stem cells from other organs, like the spleen, can be stimulated with soluble Wnt proteins (Reya, 2003; Reya, et al., 2003). A major problem has been the unavailability of pure Wnt proteins. In this respect, the recentlyreported purification of Wnt3a will certainly facilitate progress. Quite intriguingly, lipid modification of Wnt by palmitoylation was shown to be essential for activating the canonical Wnt signaling pathway (Willert, et al., 2003). Thus, a lipid modification generally associated with intracellular targeting of proteins to 
membrane microdomains (discussed further on) now also appears important for extracellular ligand-receptor interactions.

\section{Signaling associated with changes in cell morphology}

Cadherins are calcium-dependent cell adhesion molecules that interact homophilically with cadherins of neighboring cells to mediate cell-cell interactions crucial to embryonic development (Wheelock and Johnson, $2003 \mathrm{a}, 2003 \mathrm{~b})$. This group of proteins is responsible for the formation of adherens junctions in epithelial cells where the actin cytoskeleton plays an important role in establishing cell polarity and shape. In this sequence, $\alpha$-catenin represents an important intermediate that links both directly and indirectly the cadherin/ $\beta$-catenin complex to the actin cytoskeleton (Yokoyama, et al., 2001). Since remodeling of the actin cytoskeleton is orchestrated by Rho family GTPases that are localized to cell-cell contact sites, a role for these proteins in epithelial-mesenchymal transition has been proposed. Specifically, for maintenance of the epithelial state, Rac is recruited and activated upon cadherin engagement, while RhoA is inactivated to allow new contacts to be formed (Braga, et al., 1999; Noren, et al., 2001; Arthur, et al., 2002).

At the International Symposium last year, Burridge and co-workers presented evidence indicating that RhoA activity was suppressed upon cadherin engagement; however, the mechanisms by which cadherin activation would lead to changes in activity of small GTPases was unknown at the time. These small $G$ proteins, like other members of the Ras protein superfamily which participate in a large variety of functions -including regulation of cell growth, cell cycle progression, gene transcription, organization of the actin cytoskeleton, cell migration, vesicle trafficking, and nuclear transport- are targeted to the membrane by posttranslational attachment of prenyl groups by geranyl-geranyltransferases (GGTases). Despite such diverse functions, all small G-proteins share a common mode of activation by guanine nucleotide exchange. Cycling between the inactive (GDP-bound) and active (GTP-bound) forms is regulated by guanine nucleotide exchange factors (GEFs) and GTPaseactivating proteins (GAPs). Guaninenucleotide dissociation inhibitors (GDIs) prevent nucleotide dissociation and thereby control the cycling of Rho GTPases between membrane and cytosol. Active, GTP-bound GTPases interact with effector molecules to mediate various cellular responses (Schmidt and Hall, 2002). Recently, Burridge's group addressed the question of how cadherin inactivates Rho and provided evidence indicating that tyrosine phosphorylation of p190RhoGAP, a GTPase activating protein for Rho, is induced by Src-family members upon cadherin ligation. Phosphorylation of p190RhoGAP increases binding to p120RasGAP, which is important in cell movement, actin cytoskeleton reorientation and cell polarization (Kulkarni, et al., 2000). Phosphorylated p190RhoGAP activates the intrinsic GTPase activity of Rho and in this manner is responsible for decreased RhoA activity levels, reduced tension and contractility as well as increased formation of cell-cell adherens junctions (Noren, et al., 2003).

In epithelia, cells interact with one another as well as with the extracellular matrix. Integrin receptors, another family of transmembrane cell adhesion receptors, mediate the latter interaction. Upon activation, integrins reorganize the actin cytoskeleton and promote changes in cell morphology. The Rho family of small GTPases are key regulators of such integrin-mediated events, and interaction of integrins with the extracellular matrix protein fibronectin leads to RhoA inactivation in a manner similar to that observed upon cadherin engagement (Arthur, et al., 2002). Complex formation, observed as the result of cell-cell and cellmatrix interactions, is a highly-regulated event that relies on the specificity of different motifs present in each protein. For example, Rac1 binding to the adapter protein Crk requires an $\mathrm{SH} 3$ domain of $\mathrm{Crk}$ 
and a proline-rich domain present in the Cterminal region of Rac1. Moreover, this same Rac1 C-terminal region (amino acids 185-187) binds to phosphatidylinositol 4phosphate 5-kinase, a protein critically involved in regulating actin polymerization. In doing so, this region controls both localization of Rac1 and downstream signaling events (Van Hennik, et al., 2003)

Integrins are a family of $\alpha \beta$ heterodimers that typically interact with extracellular matrix proteins and also mediate cell-cell interactions by binding to membrane proteins of the Immunoglobulin superfamily, such as L1 and Thy-1 (Montgomery, et al., 1996, Leyton, et al., 2001). Both proteins are present in neuronal cells and are known interacting partners of $\beta_{3}$-containing integrins. In astrocytes, a $\beta_{3}$ integrin interacts with cellular Thy-1 to induce tyrosine phosphorylation of focal adhesion kinase and p130Cas, thereby promoting focal adhesions and stress fiber formation (Leyton, et al., 2001). Morphological changes induced in this case seem also to implicate the modulation of Rho family GTPases (Ávalos, et al., 2002). However, it is not clear currently whether the complex signaling events that occur upon focal adhesion formation are the same when induced by cell-matrix or cell-cell interactions.

ADP-ribosylating factors (Arfs) are another family of small GTPases implicated particularly as regulators of vesicular transport that were discussed at the symposium in 2002. An interesting point that was raised concerned the common ability of Arfs and Rho family members to mediate cell adhesion, as well as cytoskeletal changes (Hawadle, et al., 2002). This property is generally attributed to Arf 6, but not other members, such as Arf 1 or Arf 5. In agonist-stimulated cells, Arf 6 is transported to the plasma membrane in Rac-1-containing endosomal vesicles. This results in a Raclike phenotype and down-regulation of stress fiber formation by inhibiting Rho activity. None of these events are observed in the presence of a dominant negative Arf 6, which prevents endosomal recycling. Moreover, in cells expressing a constitutively active Arf 6 protein, stress fiber formation upon lysophosphatidic acid treatment is blocked (Boshans, et al., 2000). Thus, such small GTPases play an important role in cytoskeletal organization and actin remodeling by facilitating translocation to the plasma membrane of vesicles containing supramolecular complexes formed upon agonist stimulation.

As previously stated, Rho-family proteins are implicated as regulators of a wide range of biological processes. Given that diminished adhesion and higher cell motility are properties characteristic of cancer cells at later stages in tumor development, the link between Rho molecules and cellular transformation is apparent. Interestingly, however, studies using mutant mouse models provide evidence for a role of Rho family proteins in multiple stages of tumor initiation and progression, including regulation of cell growth and survival, but not necessarily as mediators of enhanced cell motility and the invasive behavior of tumor cells, as might be expected. For more details, the reader is referred to an excellent review where the role of Rho proteins in cancer is discussed (Malliri and Collard, 2003).

As illustrated by these examples, signaling events are highly dependent on protein-protein interactions as one possibility to determine correct spatial and temporal positioning of the elements required. Such interactions play a crucial role in controlling signaling. Thus, pathological situations easily may arise from a loss of regulation due to alterations in such interactions.

\section{Membrane microdomains as important signaling compartments}

The significance of molecular organization in signaling is perhaps most appropriately illustrated by the role caveolin- 1 currently is thought to play in the development of diseases like cancer. Caveolins are the major coat proteins of 50-100 nm plasma membrane invaginations, called caveolae, found in a large variety of cells. Many functions have been attributed to this cellular compartment, but in recent years they have attracted 
considerable attention due to their potential role as 'signalosomes,' cellular sites where a large variety of signaling components are present and thought to interact. A considerable amount of caveolin-related research has focused on caveolin-1. Caveolin1 functions as a scaffolding protein that interacts with many other proteins involved in signal transduction and frequently inhibits their activities. Alternatively, caveolin-1 presence has also been shown to promote degradations of proteins via the proteasome pathway (Felley Bosco et al, 2000; 2002). Considering these properties it is perhaps not surprising that caveolin-1 down-regulation favors cell transformation and that reexpression of the protein suppresses the transformed phenotype in a large number of cellular settings. In addition, levels of this protein are reduced in transformed cells and in several human cancers, suggesting that elimination of the protein favors tumor development. These findings implicate caveolin-1 as a functional tumor suppressor. Precisely how this protein modulates cellular function is an area of intense research. The emerging theme is that caveolin-1 function depends to a considerable extent on the cellular context and the stage at which expression is suppressed and/or re-expression is triggered (reviewed in Quest, et al., 2004).

Microdomains of the plasma membrane, like caveolae, are enriched in cholesterol and sphingolipids. However, it is important to note that cells lacking caveolin also contain these functional domains. Indeed, proteins anchored to the membrane via a glycosylphosphatidylinositol lipid are located in microdomains of the membrane with similar properties but lack caveolins and are referred to as lipid rafts. These may exist side by side with caveolae in a cell; however, due to their similar lipid composition, their isolation as separate entities is still a difficult task (see discussion in Bender, et al., 2002 and Quest, et al., 2004).

An example of cells lacking caveolin-1 expression and caveolae is $\mathrm{T}$ cells. Lipid rafts in the $T$ cell membrane are thought to play an important role in the formation of $T$ cell receptor (TCR) signaling complexes upon engagement of the receptor. Several pieces of evidence support this notion. For example, the linker for activation of $\mathrm{T}$ cells (LAT) is a protein that is highly phosphorylated on tyrosine upon TCR engagement (Leyton, et al., 1999). Targeting of this protein to lipid rafts via lipid modification is essential for TCR signaling to occur (Zhang, et al., 1998a, 1998 b, 1999). On the other hand, whether the presence of cholesterol or sphingolipids -both major components of lipid rafts- is necessary to maintain raft integrity and whether the latter is required for efficient TCR signaling is a controversial issue. Experiments employed to assess such possibilities often utilize drugs that disrupt raft structure and impair the TCR response. However, recent studies reveal that the side effects of such drugs could explain the data obtained and that TCR signaling indeed may occur in a manner independent of raft organization (Pizzo, et al., 2002; Nagafuku, et al., 2003).

In light of such findings, experiments using confocal microscopy and video imaging may represent better experimental approaches to assess the importance of membrane microdomains in cellular signaling. Indeed, such methods have allowed quantification of the amount of lipid rafts that coalesce at the immunological synapse (IS) upon TCR engagement. Given the small amount of microdomains detected at the center of the supramolecular activation complex only peripheral rafts have been suggested to migrate to the center of the IS during activation (Burack, et al., 2002). In doing so, membrane microdomains would serve as a vector for targeting groups of signaling molecules to the IS, whereby translocation in this case requires an intact cytoskeleton, the activation of phosphatidylinositol 3-kinase, and myosin motor proteins (Jordan and Rodgers, 2003).

Data discussed at the symposium in 2002 indicated that, although not essential for $T$ cell activation, formation of the IS was important for TCR signaling (Faroudi, et al., 2002; Zaru, et al., 2002). However, whether IS formation is a dynamic process or whether the IS is maintained as a stable entity until the $\mathrm{T}$ cell responds remained an issue. Recent evidence implicates the IS as a dynamic entity 
that can integrate signals of intermittent strength in time to yield complete $\mathrm{T}$ cell activation (Faroudi, et al., 2003).

The number of proteins that are known to participate in the TCR signaling complex is constantly increasing, and many of the components are regulated by phosphorylation. While the precise composition remains to be defined, a consensus does exist as to which proteins are excluded from this complex. CD45, a tyrosine phosphatase important in inhibition of the active complex is thought to represent one such example (Magee, et al., 2002). However, recent evidence indicates that a small percentage of this phosphatase is present in lipid rafts of non-stimulated $\mathrm{T}$ cells and is required there to maintain the inactive state. Once the T cell is activated, CD45 is excluded from the IS thereby promoting full activation of the kinases involved (Edmonds and Ostergaard, 2002).

Imaging techniques such as fluorescence resonance energy transfer (FRET) microscopy to study the dynamics of lipid rafts in living cells indicate that not only proteins are part of such complexes: phosphatidylinositol lipids are also present in the IS (Parmryd, et al., 2003). This comes as no surprise since LAT, an essential component of the IS, is known to recruit PLC $\gamma$ to the IS once phosphorylated on tyrosine (Zhang, et al., 1998a). PI(4,5) $\mathrm{P}_{2}$ serves as a substrate for PLC $\gamma$ to generate inositol 3,4,5-trisphosphate $\left(\mathrm{IP}_{3}\right)$ and diacylglycerol (DAG). Both second messengers are enriched at the plasma membrane in lipid rafts (Parmryd, et al., 2003).

Inositol lipids are known targets of lipidbinding domains present in many proteins. These protein modules mediate membrane translocation in response to receptor stimulation by acting like soft "Velcro" that reversibly recruits molecules to the signaling site via protein-lipid interactions. Pleckstrin homology (PH) and Phox homology (PX) domains are well-described protein modules that mediate such lipid interactions involved in transient association of signaling proteins with membranes (Lemmon, 2003; Wientjes and Segal, 2003). The combined utilization of multiple protein-protein and protein-lipid interaction modules in signaling proteins permits very precise recruitment in time and space of such proteins to the site required.

Lipid modifications of proteins are further important mediators of membrane interactions. Although not all are reversible by nature, these protein modifications generally permit transient membrane interactions. S-palmitoylation, the only reversible covalent lipid modification known to date, is present in a number of signaling proteins and is thought to play an important role in targeting signaling proteins not only to membranes in general, but more specifically to membrane microdomains (reviewed in Patterson, 2002). Examples of proteins recruited to the IS in $\mathrm{T}$ cell signaling are the Src-family kinase fyn, and the adaptor protein LAT (Zhang, et al., 1998b; Van't Hof and Resh, 1999). Other lipid modifications of proteins, such as prenylation and myristoylation are by themselves generally not sufficient for efficient membrane association; hence, they are often employed in conjunction with palmitoylation for membrane targeting (reviewed in Fivaz and Meyer, 2003). In this manner, the combination of lipid modifications permits not only control of membrane localization per se, but also the control of protein distribution within membranes.

Rather unexpectedly, lipid modifications are suggested to also target nuclear receptors to the membrane. Such receptors owe their name to the fact that they are localized and activated within cells by membrane-permeable hydrophobic ligands. The canonical signaling pathway of an activated steroid receptor is to enter the nucleus and there regulate gene transcription by forming multiprotein complexes that promote or suppress transcription (reviewed in Hart, 2002). Receptors of this kind are now known also to be present at the plasma membrane where they are involved in formation of 'steroid signaling complexes' that generate fast non-genomic responses (Acconcia, et al., 2003, Li, et al., 2003). Estrogen receptor (ER) 46, a truncated form of the 66 $\mathrm{kDa}$ ER is generated by alternative splicing and recruited to plasma membrane caveolae 
in a palmitoylation-dependent manner ( $\mathrm{Li}$, et al., 2003). Estrogen binding to ER46 rapidly induces nitric oxide release via a phosphatidylinositol 3-kinase/Akt/ endothelial nitric-oxide synthase (eNOS) pathway in human endothelial cells (Haynes, et al., 2000).

Currently, evidence for the existence of membrane-localized steroid hormone receptors that differ in their structure from classical forms is increasing (reviewed in Haynes, et al., 2002). Another example is found in muscle cells, where testosterone generates a fast response involving Gprotein coupled receptors, IP3-mediated $\mathrm{Ca}^{2+}$ release, and activation of the Ras/ MEK/ERK pathway (Estrada, et al., 2003).

\section{Calcium signaling}

Thus, steroid receptors -once thought to signal exclusively via effects in the nucleusare now known to elicit responses via processes dependent on localization in microdomains of the plasma membrane. Alternatively, signals once thought to operate primarily in the cytoplasm, such as elevation of intracellular $\mathrm{Ca}^{2+}$, are now also found in the nucleus where they are linked functionally to processes such as gene transcription. A local store of calcium present in the recentlydefined "nucleoplasmic reticulum" is proposed to contain IP3-Rs that are activated locally by IP3 and release calcium within the nucleus in a compartmentalized fashion (Araya, et al., 2003; Echevarría, et al., 2003). This nuclear calcium release mechanism appears to be independent of cytosolic $\mathrm{Ca}^{2+}$ release because it is detected more rapidly and displays higher sensitivity to IP3 (Leite, et al., 2003). Thus, cytosolic and nuclear calcium responses appear to be distinct, independently-regulated events.

In skeletal muscle cells, membrane depolarization triggers a sequence of signaling events that starts at the plasma membrane and ends in the nucleus (reviewed in Jaimovich and Carrasco, 2002). Specifically, potassiuminduced depolarization of myotubes in culture leads to induction of early gene expression via mechanisms that depend on the phosphorylation of CREB and ERK. Such phosphorylation events are mediated by calcium signals in both the cytoplasm and the nucleus (Carrasco, et al., 2003). Rather interestingly, CREB phosphorylation and activation was shown also to occur via a process that involves selective translocation of PKC $\alpha$ to the nucleus (Cárdenas, et al., 2002).

Clearly, $\mathrm{Ca}^{2+}$ signaling occurs in a highly-compartmentalized fashion and is temporally regulated to yield a large variety of cellular responses as discussed at the symposium in 2002 (Petersen, 2002). In this context, a recent international workshop entitled "Calcium Release and Cellular Calcium Signaling Domains" was held in Marbella, Chile from Sept. 28 to Oct. 2, 2003. The highlights of this meeting were the contributions by well-known scientists from many countries indicating how different calcium signaling pathways are mediated by calcium release from intracellular stores. A compilation of the abstracts of papers presented at this workshop as well as a series of minireviews from all the session chairs are provided in this volume and the following issue of Biological Research, respectively.

Given the vast number of processes where $\mathrm{Ca}^{2+}$ signals are implicated (see, for instance, the July 2003 issue of Nature Reviews in Molecular and Cellular Biology), it is not surprising that disregulation of calcium homeostasis may lead to a number of diseases. For example, under normal conditions $\mathrm{Ca}^{2+}$ signals regulate enzyme and fluid secretion as well as cell division and programmed cell death of pancreatic acinar cells. Alterations in calcium signals in these cells lead to trypsin activation and autodigestion of the gland, as is observed in disease state (Raraty, et al., 2000). Such calcium signals might result as a consequence of bile entering the pancreas by a reflux process (Voronina, et al., 2002).

Additional examples underscoring the importance of calcium transients in this respect are malignant hyperthermia (a toxic response to anesthetics) and central core disease, which is a muscle myopathy. The poorly-controlled calcium signals linked to these diseases are due to mutations in the Ryanodine receptor 1 ( $\mathrm{RyR} 1)$, a $\mathrm{Ca}^{2+}$ release channel. In cardiac muscle, a 
voltage-activated channel at the plasma membrane allows the entry of calcium and leads to local activation of the RyR in the sarcoplasmic reticulum (SR), which increases the calcium concentration further to levels required to bind to the myofilament protein troponin $\mathrm{C}$ and trigger contraction (Bers, 2002).

In skeletal muscle cells, on the other hand, increases in intracellular calcium are due to activation of a calcium-independent RyR via membrane depolarization and a voltage-sensor dependent process (Ríos and Pizarro, 1991). Despite being quite distinct in the way they are activated, RyR isoforms present in cardiac and muscle cells are both sensitive to redox regulation (Hidalgo, et al., 2002). Such redox-controlled regulation of calcium is likely to be important both under normal physiological conditions, as well as in development of pathological situations, the latter with fatal consequences for the respective cells, since augmented levels of reactive oxygen species may trigger excessive calcium release by sustained RyR activation (Aracena, et al., 2003; Sánchez, et al., 2003).

\section{Cell death-related signaling events}

Not surprisingly, intracellular calcium homeostasis is also important for cell survival. The first insights implicating calcium signaling in death-related events where obtained using cardiac myocytes in 1974 (Fleckenstein, et al., 1974). Although at the time the effect was attributed to an excessive influx of $\mathrm{Ca}^{2+}$ into the cells, recent findings indicate that preventing calcium uptake to the ER may be sufficient to trigger apoptosis as part of a stress response (reviewed in Orrenius, et al., 2003). Recent experiments in cardiac myocytes suggest that apoptosis observed in response to hyperosmotic stress is sensitive to the osmolyte nature and requires the activation of aldose reductase (a key enzyme in polyol pathway), as well as a decrease in glutathione levels. In addition, the presence of antioxidants prevents cardiomyocyte death under such conditions (Gálvez, et al., 2003). To what extent these changes in redox potential may promote calcium release from internal stores, via RyRs for instance, remains an open question.

Interestingly, well-established cardioprotective growth factors, such as IGF-1, are likely to involve calcium-dependent signaling events, given that IGF-1 triggers both nuclear and cytosolic $\mathrm{Ca}^{2+}$ transients, via an IP3-dependent mechanism (Ibarra, et al., 2003). Intracellular elevation of calcium in an inappropriate manner can clearly trigger cell death; however, the precise targets that would account for calcium toxicity have been difficult to identify due to the vast number of cellular functions that are regulated by this cation. In addition, it is becoming increasingly clear that the intracellular distribution of other ions changes as part of the cellular response to certain stimuli or injury. Thus, it appears that the sum of all such ion movements determines the nature of the cellular response (reviewed in Barros, et al., 2002).

Bcl-2 family members are divided into two major categories, namely: those with activities that promote either cell survival or cell death. Members from both groups are localized in ER and mitochondrial membranes where they represent critical regulators of the calcium content in these cellular compartments. Apparently, this balance of activities regulates $\mathrm{Ca}^{2+}$ content in the ER and the transfer of $\mathrm{Ca}^{2+}$ from the ER to mitochondria (Foyouzi-Youssefi, et al., 2000; Pinton, et al. 2000; Wang, et al., 2001; Thomenius, et al., 2003). Interestingly, not only calcium pools in membrane-bound compartments appear important; a matrix-associated, cytosolic calcium pool was identified recently as playing a role in hydrogen peroxideinduced cell death in HeLa cells (Castro, et al., 2004).

In general terms, apoptotic cell death may be initiated via either intrinsic or extrinsic mechanisms. Calcium-related events are often linked to the intrinsic pathway, when cells die in response to "stress" conditions. Currently, three types of stimuli are distinguished that lead to cell death via intrinsic mechanisms. The first, observed in response to arachidonic acid, ceramide or 
oxidative stress, requires calcium release from the ER without involvement of the mitochondria. The second involves "BH3only" death promoting Bcl-2 family members. In particular, the presence of Bax or Bak in the mitochondria membrane is required, but neither calcium release from the mitochondria or the ER triggers cell death. Finally, cytotoxic agents like etoposide, staurosporine, or Brefeldin A, as well as TCR stimulation in T cells, represent a third type of death-promoting stimuli involving calcium and Bax/Bak in both ER and mitochondria membranes (Scorrano, et al., 2003).

Apoptosis initiated via the extrinsic pathway involves interactions of specific ligands with cell surface receptors (Razik and Cidlowski, 2002; Wajant, 2002; Barnhart, et al., 2003). As a consequence, initiator caspases are activated which then cleave and activate the executioner caspases, responsible for triggering the process of organized cell destruction with highly-characteristic events, including cleavage of many intracellular proteins like PARP, chromatin condensation, nuclear fragmentation and DNA degradation, as well as externalization of phosphatidylserine (PS) (Rathmell and Thompson, 1999). While the downstream events observed are often similar, multiprotein complexes involved in the activation of the initiator caspases are distinct. The extrinsic pathway requires formation of the death-induced signaling complex (DISC) at the plasma membrane for activation of the initiator caspase-8. In contrast, cytochrome c release from the mitochondria and formation of the "apoptosome" complex lead to activation of caspase-9. Subsequently activated executioner caspases, such as caspase-3, can be identical for both pathways (Razik and Cidlowski, 2002).

Independent of the cell stimuli, another characteristic feature of all types of apoptosis is cell shrinkage that occurs as a consequence of dramatic changes in $\mathrm{Na}+$ and $\mathrm{K}+$ ion fluxes and the associated movement of water to the cell exterior (Bortner, et al., 1997). The movements of monovalent ions during cell death and alterations in these ions that may be related to changes in cell volume have been discussed recently (Razik and Cidlowski, 2002, Simon, et al., 2002). Interestingly, however, in experimental situations in which cells undergo all changes generally associated with apoptosis except cell shrinkage, the prevailing death mode is still apoptosis, indicating that decreased cell volume is not required for programmed cell death to occur (Bortner and Cidlowski, 2003).

In vivo, apoptotic cells disintegrate into apoptotic bodies without releasing any cellular debris, thereby avoiding inflammation (Sauter, et al., 2000). Recognition of apoptotic bodies by macrophages involves scramblase-mediated exposure of PS on the outer plasma membrane surface. However, PS recognition alone does not appear sufficient to complete the process. Successful engulfment requires release of a phospholipid, possibly lysophosphatidylcholine (LPC), which acts as a chemoattractant. This phospholipid, liberated in a caspase- 3 dependent fashion, is required as an additional signal by monocytes and primary macrophages in order to be targeted to the correct place, to recognize apoptotic cells, and to complete the engulfment process (Lauber, et al., 2003).

In contrast to apoptosis, the programmed version of cell death, necrosis is considered accidental by nature and the unfortunate consequence of injury or ischemia. Unlike apoptosis, uncontrolled increases in cell volume eventually disrupt the plasma membrane and liberate cell contents at random (Barros, et al., 2002; Simon, et al., 2002). In vivo, necrotic cell death leads to inflammation, which on a large scale is not desirable to an organism. Thus, during development, or for tissue homeostasis in multicellular organisms, apoptosis is employed predominantly to eliminate unwanted cells. Despite such preference for apoptosis due to its apparent advantages, it is now becoming increasingly clear that necrosis need not to be accidental and may occur as a regulated event that in some cases is triggered in parallel with apoptosis in the same population of cells (see Hetz, et al., 2002 and references therein).

Using A20 and Jurkat T cells as working models, FasL, acting via the Fas receptor, 
was shown to induce both necrosis and apoptosis in a caspase-8-dependent manner (Hetz, et al., 2002). In necrotic cells, downstream activation of caspase-3 was not observed. Rather, delayed elevation of intracellular ceramide concentration as a consequence of sphingolipid scrambling was linked mechanistically to this form of cell death (Hetz, et al., 2002). Given that necrosis may also occur when cells are not engulfed during apoptosis and that PS was also present on the surface of necrotic cells in these experiments, it is tempting to speculate that the absence of a chemoattractant in vivo due to lack of effector caspase activation might result in an inflammatory response.

Externalization of PS is thus observed in both apoptotic and necrotic cells in culture. Interestingly, it has also been reported to occur in cell activation and in ageing and is basically associated with all processes that may possibly implicate disposal of unwanted cells (Henson, et al., 2001). A question arises as to how phospholipid localization to the inner leaflet of the plasma membrane is controlled. As one possibility, increase in intracellular calcium inactivates the aminophospholipid translocase activity required for maintaining lipid asymmetry in the membrane. Phospholipid scramblases, enzymes that catalyze bidirectional movement of membrane phospholipids, are regulated by calcium-dependent and independent mechanisms (Williamson, et al., 2001). In any case, loss of lipid asymmetry becomes apparent by exposure of PS in the outer leaflet of the membrane bilayer (reviewed in Bevers, et al., 1999). PS exposure is reportedly also a caspasedependent process (Yu, et al., 2000). Activation of the pro-survival serinethreonine kinase Akt1 inhibits PS flipping to the outside by preventing activation of caspases and thereby helping to maintain cellular integrity (Kang, et al., 2003). As may be expected, scramblase overexpression in $\mathrm{CHO}$ cells leads to elevated PS synthesis and externalization. Perhaps more interestingly, this phenomenon is associated with high basal levels of cell death and increased sensitivity of cells to undergo apoptosis upon cellular stress (Yu, et al., 2003). Taken together these results implicate PS externalization both as a downstream consequence of caspase activation in the process of apoptosis, as well as an event that per se can favor cell death.

In summary, this limited discussion of recent developments concerning a few signaling pathways and associated cellular systems hopefully underscores the importance of multiprotein complex formation in cellular signaling, the major theme of an international symposium held September 2002 in Santiago, Chile. Perhaps the most fascinating emerging subject is the importance of membranes in many aspects of signaling. Some 25 years ago, the observation that DAG serves as a physiologically-relevant activator of PKC gave rise to the concept of lipid second messengers, thereby completely changing the way lipids were viewed (reviewed in Quest, et al., 1996). Now, with the description of membrane microdomains (rafts, caveolae), we are beginning to appreciate the complexity of lipid organization within membranes and the role these highly-dynamic surfaces play as platforms for the assembly of many of the protein complexes employed in signaling. Indeed, such surface-bound complex assembly is not limited to the plasma membrane only. Intracellular membrane surfaces such as endosomes also are employed for the assembly of complexes related, for instance, to growth factor signaling (Wang, et al., 2004). Given such insight and the already well-documented role of intracellular compartments, such as mitochondria and the ER in addition to the plasma membrane, in cell death-related events, appreciation of the importance of membranes in signaling can be expected to increase considerably in the near future. Together with the wealth of sequence information available in databases that will continue to help unravel the secrets of modular protein organization, we suspect that compartmentalization and complex formation will remain recurrent themes in cellular signaling and disease for many years to come. 


\section{ACKNOWLEDGEMENTS}

Work from this laboratory was supported by the following awards: FONDECYT grant \#1020585, FONDAP 15010006, Collaborative Wellcome Trust project 064911/Z/01/z and ICGEB grant CRP/ CH100-05 (to AFGQ) as well as FogartyNIH grant \#1-R03-TW06024-01 and FONDECYT grant \#1040390 (to LL).

\section{REFERENCES}

ACCONCIA F, BOCEDI A, ASCENZI P, MARINO M (2003) Does palmitoylation target estrogen receptors to plasma membrane caveolae? IUBMB Life 55: 33-5

ARACENA P, SÁNCHEZ G, DONOSO P, HAMILTON SL, HIDALGO C (2003) S-glutathionylation decreases Mg2+ inhibition and S-nitrosylation enhances $\mathrm{Ca} 2+$ activation of RyR1 channels. J Biol Chem 278: 42927-35

ARAYA R, LIBERONA JL, CÁRDENAS JC, RIVEROS $\mathrm{N}$, ESTRADA M, POWELL JA, CARRASCO MA, JAIMOVICH E (2003) Dihydropyridine receptors as voltage sensors for a depolarization-evoked, IP3Rmediated, slow calcium signal in skeletal muscle cells. J Gen Physiol 121: 3-16

ARTHUR WT, NOREN NK, BURRIDGE K (2002) Regulation of Rho family GTPases by cell-cell and cell-matrix adhesion. Biol Res 35: 239-46

ÁVALOS AM, LABRA CV, QUEST AF, LEYTON L (2002) Signaling triggered by Thy-1 interaction with beta 3 integrin on astrocytes is an essential step towards unraveling neuronal Thy-1 function. Biol Res 35: $231-8$

AYBAR MJ, GLAVIC A, MAYOR R (2002) Extracellular signals, cell interactions and transcription factors involved in the induction of the neural crest cells. Biol Res 35: 267-75

AYBAR MJ, MAYOR R (2002) Early induction of neural crest cells: lessons learned from frog, fish and chick. Curr Opin Genet Dev 12: 452-8

AYBAR MJ, NIETO MA, MAYOR R (2003) Snail precedes slug in the genetic cascade required for the specification and migration of the Xenopus neural crest. Development 130: 483-94

BARNHART BC, ALAPPAT EC, PETER ME (2003) The CD95 type I/type II model. Semin Immunol 15:185-93

BARROS L, CASTRO J, BITTNER C (2002) Ion movements in cell death: from protection to execution. Biol Res 35: 209-14

BENDER F, MONTOYA M, MONARDES V, LEYTON L, QUEST AF (2002) Caveolae and caveolae-like membrane domains in cellular signaling and disease: identification of downstream targets for the tumor suppressor protein caveolin-1. Biol Res 35: 151-67

BERS DM (2002) Cardiac excitation-contraction coupling. Nature 415: 198-205

BEVERS EM, COMFURIUS P, DEKKERS DW, ZWAAL RF (1999) Lipid translocation across the plasma membrane of mammalian cells. Biochim Biophys Acta 1439: $317-30$

BORTNER CD, HUGHES FM, JR., CIDLOWSKI JA (1997) A primary role for $\mathrm{K}+$ and $\mathrm{Na}+$ efflux in the activation of apoptosis. J Biol Chem 272: 32436-42
BORTNER CD, CIDLOWSKI JA (2003) Uncoupling cell shrinkage from apoptosis reveals $\mathrm{Na}$ Influx is required for volume loss during programmed cell death. J Biol Chem 278: 39176-84

BOSHANS RL, SZANTO S, VAN AELST L, D'SOUZASCHOREY C (2000) ADP-ribosylation factor 6 regulates actin cytoskeleton remodeling in coordination with Rac1 and RhoA. Mol Cell Biol 20: 3685-94

BRAGA VM, DEL MASCHIO A, MACHESKY L, DEJANA E (1999) Regulation of cadherin function by Rho and Rac: modulation by junction maturation and cellular context. Mol Biol Cell 10: 9-22

BURACK WR, LEE KH, HOLDORF AD, DUSTIN ML, SHAW AS (2002) Cutting edge: quantitative imaging of raft accumulation in the immunological synapse. J Immunol 169: 2837-41

CÁRDENAS C, BUCHUK D, MULLER M, QUEST AFG, JAIMOVICH E, CARRASCO MA (2002) CREBS phosphorylation is PKC-dependent in depolarized skeletal muscle cells. Biol Res 35: R-67

CARRASCO MA, RIVEROS N, RÍOS J, MULLER M, TORRES F, PINEDA J, LANTADILLA S, JAIMOVICH E (2003) Depolarization-induced slow calcium transients activate early genes in skeletal muscle cells. Am J Physiol Cell Physiol 284: C1438-47

CASTRO J, BITTNER C, HUMERES A, MONTECINOS V, VERA J, BARROS L (2004) A cytosolic source of calcium unveiled by hydrogen peroxide with relevance for epithelial cell death. Cell Death Differ 11: 468-78

ECHEVARRÍA W, LEITE MF, GUERRA MT, ZIPFEL WR, NATHANSON MH (2003) Regulation of calcium signals in the nucleus by a nucleoplasmic reticulum. Nat Cell Biol 5: 440-6

EDMONDS SD, OSTERGAARD HL (2002) Dynamic association of CD45 with detergent-insoluble microdomains in T lymphocytes. J Immunol 169: 5036-42

ESTRADA M, ESPINOSA A, MULLER M, JAIMOVICH E (2003) Testosterone stimulates intracellular calcium release and mitogen-activated protein kinases via a $G$ protein-coupled receptor in skeletal muscle cells. Endocrinology 144: 3586-97

FAROUDI M, SARU R, FAVIER B, VALITUTTI S (2002) New insights to the functional role of the $\mathrm{T}$ cellantigen presenting cell immunological synapse. Biol Res 35: 133-7

FAROUDI M, ZARU R, PAULET P, MULLER S, VALITUTTI S (2003) Cutting edge: T lymphocyte activation by repeated immunological synapse formation and intermittent signaling. J Immunol 171: 1128-32

FELLEY-BOSCO E, BENDER F, COURJALT-GAUTIER F, BRON C, QUEST AFG (2000) Caveolin-1 downregulates inducible nitric oxide synthase $\left(\mathrm{iNO}_{\mathrm{s}}\right)$ via the proteasome pathway in human colon carcinoma cells. Proc. Natl acad Sci USA 97: 14334-9.

FELLEY-BOSCO E, BENDER F, QUEST AFG (2002) Caveolin-1 mediated post-transcriptional regulation of inducible nitric oxide synthase in human colon carcinoma cells. Biol Res 35: 169-76.

FIVAZ M, MEYER T (2003) Specific localization and timing in neuronal signal transduction mediated by protein-lipid interactions. Neuron 40: 319-30

FLECKENSTEIN A, JANKE J, DORING HJ, LEDER O (1974) Myocardial fiber necrosis due to intracellular $\mathrm{Ca}$ overload-a new principle in cardiac pathophysiology. Recent Adv Stud Cardiac Struct Metab 4: 563-80

FOYOUZI-YOUSSEFI R, ARNAUDEAU S, BORNER C, KELLEY WL, TSCHOPP J, LEW DP, DEMAUREX N, KRAUSE KH (2000) Bcl-2 decreases the free Ca2+ 
concentration within the endoplasmic reticulum. Proc Natl Acad Sci U S A 97: 5723-8

GÁlVEZ AS, ULLOA JA, CHIONG M, CRIOLLO A, EISNER V, BARROS LF, LAVANDERO S (2003) Aldose reductase induced by hyperosmotic stress mediates cardiomyocyte apoptosis: differential effects of sorbitol and mannitol. J Biol Chem 278: 38484-94

HABAS R, DAWID IB, HE X (2003) Coactivation of Rac and Rho by Wnt/Frizzled signaling is required for vertebrate gastrulation. Genes Dev 17: 295-309

HAINES N, IRVINE KD (2003) Glycosylation regulates Notch signaling. Nat Rev Mol Cell Biol 4: 786-97

HART S (2002) Modulation of nuclear receptor dependent transcription. Biol Res 35: 295-303

HAWADLE M, FOLARIN N, MARTIN M, JACKSON T (2002) Cytohesins and centaurins control subcellular trafficking of macromolecular signaling complexes: Regulation by phosphoinositides and ADPRibosylation Factors. Biol Res 35: 247-65

HAYNES MP, SINHA D, RUSSELL KS, COLLINGE M, FULTON D, MORALES-RUIZ M, SESSA WC, BENDER JR (2000) Membrane estrogen receptor engagement activates endothelial nitric oxide synthase via the PI3-kinase-Akt pathway in human endothelial cells. Circ Res 87: 677-82

HAYNES MP, LI L, RUSSELL KS, BENDER JR (2002) Rapid vascular cell responses to estrogen and membrane receptors. Vascul Pharmacol 38: 99-108

HENDRIKS B, REICHMANN H (2002) Wnt signaling: A complex issue. Biol Res 35: 277-86

HENSON PM, BRATTON DL, FADOK VA (2001) The phosphatidylserine receptor: a crucial molecular switch? Nat Rev Mol Cell Biol 2: 627-33

HETZ C, HUNN M, ROJAS P, TORRES V, LEYTON L, QUEST A (2002) Caspase-dependent initiation of apoptosis and necrosis by the Fas receptor in lymphoid cells: onset of necrosis is associated with delayed ceramide increase. J Cell Sci 115: 4671-83

HIDALGO C, ARACENA P, SÁNCHEZ G, DONOSO P (2002) Redox regulation of calcium release in skeletal and cardiac muscle. Biol Res 35: 183-93

HONORE SM, AYBAR MJ, MAYOR R (2003) Sox10 is required for the early development of the prospective neural crest in Xenopus embryos. Dev Biol 260: 79-96

IBARRA C, ESTRADA M, CARRASCO L, CHIONG M, LIBERONA JL, CÁRDENAS C, DÍAZ-ARAYA G, JAIMOVICH E, LAVANDERO S (2004) Insulin-like growth factor-1 induces an inositol 1,4,5trisphosphate-dependent increase in nuclear and cytosolic calcium in cultured rat cardiac myocytes. J Biol Chem 279: 7554-65

JAIMOVICH E, CARRASCO M (2002) IP3 dependent $\mathrm{Ca} 2+$ signals in muscle cells are involved in regulation of gene expression. Biol Res 35: 195-202

JORDAN S, RODGERS W (2003) T cell glycolipidenriched membrane domains are constitutively assembled as membrane patches that translocate to immune synapses. J Immunol 171: 78-87

KANG JQ, CHONG ZZ, MAIESE K (2003) Critical role for Akt 1 in the modulation of apoptotic phosphatidylserine exposure and microglial activation. Mol Pharmacol 64: 557-69

KATOH M (2003) WNT2 and human gastrointestinal cancer. Int J Mol Med 12: 811-6

KIRIKOSHI H, KATOH M (2002) Expression of WNT7A in human normal tissues and cancer, and regulation of WNT7A and WNT7B in human cancer. Int J Oncol 21: 895-900

KULKARNI SV, GISH G, VAN DER GEER P, HENKEMEYER M, PAWSON T (2000) Role of p120
Ras-GAP in directed cell movement. J Cell Biol 149: 457-70

LAUBER K, BOHN E, KROBER SM, XIAO YJ, BLUMENTHAL SG, LINDEMANN RK, MARINI P, WIEDIG C, ZOBYWALSKI A, BAKSH S, XU Y, AUTENRIETH IB, SCHULZE-OSTHOFF K, BELKA C, STUHLER G, WESSELBORG S (2003) Apoptotic cells induce migration of phagocytes via caspase-3-mediated release of a lipid attraction signal. Cell 113: 717-30

LAWLER A (2003) Genetics and medicine. New institute aims to put the genome in the doctor's bag. Science 300: $1856-7$

LEITE MF, THROWER EC, ECHEVARRIA W, KOULEN $\mathrm{P}$, HIRATA K, BENNETT AM, EHRLICH BE, NATHANSON MH (2003) Nuclear and cytosolic calcium are regulated independently. Proc Natl Acad Sci U S A 100: 2975-80

LEMMON MA (2003) Phosphoinositide recognition domains. Traffic 4: 201-13

LEYTON L, QUEST AFG, BRON C (1999) Thy-1/CD3 coengagement promotes TCR signaling and enhances particularly tyrosine phosphorylation of the raft molecule LAT. Molec Immunol 36: 755-768

LEYTON L, SCHNEIDER P, LABRA CV, RÜEGG C, HETZ CA, QUEST AFG, BRON C (2001) Thy-1 binds to the integrin $\beta_{3}$ on astrocytes and triggers formation of focal contact sites. Curr Biol 11: 1028-38

LEYTON L, QUEST AF (2002) Introduction to supramolecular complex formation in cell signaling and disease. Biol Res 35: 117-25

LI L, HAYNES MP, BENDER JR (2003) Plasma membrane localization and function of the estrogen receptor alpha variant (ER46) in human endothelial cells. Proc Natl Acad Sci U S A 100: 4807-12

MAGEE T, PIRINEN N, ADLER J, PAGAKIS S, PARMRYD I (2002) Lipid rafts: cell surface platforms for $\mathrm{T}$ cell signaling. Biol Res 35: 127-31

MALLIRI A, COLLARD JG (2003) Role of Rho-family proteins in cell adhesion and cancer. Curr Opin Cell Biol 15: 583-9

MONTGOMERY AM, BECKER JC, SIU CH, LEMMON VP, CHERESH DA, PANCOOK JD, ZHAO X, REISFELD RA (1996) Human neural cell adhesion molecule L1 and rat homologue NILE are ligands for integrin alpha v beta 3. J Cell Biol 132: 475-85

MUMM JS, KOPAN R (2000) Notch signaling: from the outside in. Dev Biol 228: 151-65

NAGAFUKU M, KABAYAMA K, OKA D, KATO A, TANI-ICHI S, SHIMADA Y, OHNO-IWASHITA Y, YAMAZAKI S, SAITO T, IWABUCHI K, HAMAOKA T, INOKUCHI JI, KOSUGI A (2003) Reduction of glycosphingolipid levels in lipid rafts affects the expression state and function of glycosylphosphatidylinositol-anchored proteins, but does not impair signal transduction via the $\mathrm{T}$ cell receptor. J Biol Chem 278: 51920-7

NOREN NK, NIESSEN CM, GUMBINER BM, BURRIDGE K (2001) Cadherin engagement regulates Rho family GTPases. J Biol Chem 276: 33305-8

NOREN NK, ARTHUR WT, BURRIDGE K (2003) Cadherin engagement inhibits RhoA via p190RhoGAP. J Biol Chem 278: 13615-8

ORRENIUS S, ZHIVOTOVSKY B, NICOTERA P (2003) Regulation of cell death: the calcium-apoptosis link. Nat Rev Mol Cell Biol 4: 552-65

PARDAL R, CLARKE M, MORRISON S (2003) Applying the principles of stem-cell biology to cancer. Nat Rev Cancer 3: 895-902

PARMRYD I, ADLER J, PATEL R, MAGEE AI (2003) Imaging metabolism of phosphatidylinositol 4,5- 
bisphosphate in T-cell GM1-enriched domains containing Ras proteins. Exp Cell Res 285: 27-38

PATTERSON S (2002) Posttranslational protein Spalmitoylation and the compartmentalization of signaling molecules in neurons. Bio Res 35: 139-50

PETERSEN OH (2002) Calcium signal compartmentalization. Biol Res 35: 177-82

PINTON P, FERRARI D, MAGALHAES P, SCHULZEOSTHOFF K, DI VIRGILIO F, POZZAN T, RIZZUTO $\mathrm{R}$ (2000) Reduced loading of intracellular $\mathrm{Ca}(2+)$ stores and downregulation of capacitative $\mathrm{Ca}(2+)$ influx in Bcl-2-overexpressing cells. J Cell Biol 148: 857-62

PIZZO P, GIURISATO E, TASSI M, BENEDETTI A, POZZAN T, VIOLA A (2002) Lipid rafts and $T$ cell receptor signaling: a critical re-evaluation. Eur J Immunol 32: 3082-91

QUEST AFG, LEYTON L, PARRAGA M (2004) Caveolins, Caveolae and Lipid Rafts in Cellular Transport, Signaling and Disease. Biochem Cell Biology 82: 129-44

QUEST AFG, RABEN DM, BELL RM (1996) Diacylglycerols. Biosynthetic intermediates and lipid second messengers In: Handbook of Lipid Research, BELL RM (ed), New York, Plenumm Press. Vol.8 pp: $1-58$

RARATY M, WARD J, ERDEMLI G, VAILLANT C, NEOPTOLEMOS JP, SUTTON R, PETERSEN OH (2000) Calcium-dependent enzyme activation and vacuole formation in the apical granular region of pancreatic acinar cells. Proc Natl Acad Sci U S A 97: 13126-31

RATHMELL JC, THOMPSON CB (1999) The central effectors of cell death in the immune system. Annu Rev Immunol 17: 781-828

RAZIK M, CIDLOWSKI J (2002) Molecular interplay between ion channels and the regulation of apoptosis. Biol Res 35:

REYA T (2003) Regulation of hematopoietic stem cell selfrenewal. Recent Prog Horm Res 58: 283-95

REYA T, DUNCAN AW, AILLES L, DOMEN J, SCHERER DC, WILLERT K, HINTZ L, NUSSE R, WEISSMAN IL (2003) A role for Wnt signaling in self-renewal of haematopoietic stem cells. Nature 423: 409-14

RÍOS E, PIZARRO G (1991) Voltage sensor of excitationcontraction coupling in skeletal muscle. Physiol Rev 71: 849-908

SÁNCHEZ G, HIDALGO C, DONOSO P (2003) Kinetic studies of calcium-induced calcium release in cardiac sarcoplasmic reticulum vesicles. Biophys J 84: 2319-30

SAUTER B, ALBERT ML, FRANCISCO L, LARSSON M, SOMERSAN S, BHARDWAJ N (2000) Consequences of cell death: exposure to necrotic tumor cells, but not primary tissue cells or apoptotic cells, induces the maturation of immunostimulatory dendritic cells. J Exp Med 191: 423-34

SCHMIDT A, HALL A (2002) Guanine nucleotide exchange factors for Rho GTPases: turning on the switch. Genes Dev 16: 1587-609

SCORRANO L, OAKES SA, OPFERMAN JT, CHENG EH, SORCINELLI MD, POZZAN T, KORSMEYER SJ (2003) $\mathrm{BAX}$ and $\mathrm{BAK}$ regulation of endoplasmic reticulum $\mathrm{Ca} 2+$ : a control point for apoptosis. Science 300: 135-9

SIMCHA I, KIRKPATRICK C, SADOT E, SHTUTMAN $M$, POLEVOY G, GEIGER B, PEIFER M, BENZE'EV A (2001) Cadherin sequences that inhibit betacatenin signaling: a study in yeast and mammalian cells. Mol Biol Cell 12: 1177-88

SIMON F, VARELA D, RIVEROS A, EGUIGUREN A, STUTZIN A (2002) Non-selective cation channels and oxidative stress-induced cell swelling. Biol Res 35: 215-22

SRERE PA (1984) Why enzymes are so large? Trends Biochem Sci 9: 387-392

SUZUKI T, AOKI D, SUSUMU N, UDAGAWA Y, NOZAWA S (2000) Imbalanced expression of TAN-1 and human Notch4 in endometrial cancers. Int J Oncol 17: $1131-9$

THOMENIUS MJ, WANG NS, REINEKS EZ, WANG Z, DISTELHORST CW (2003) Bcl-2 on the endoplasmic reticulum regulates Bax activity by binding to $\mathrm{BH} 3$ only proteins. J Biol Chem 278: 6243-50

VAN HENNIK PB, TEN KLOOSTER JP, HALSTEAD JR, VOERMANS C, ANTHONY EC, DIVECHA N, HORDIJK PL (2003) The C-terminal domain of Rac1 contains two motifs that control targeting and signaling specificity. J Biol Chem 278: 39166-75

VANT HOF W, RESH MD (1999) Dual fatty acylation of p59(Fyn) is required for association with the $\mathrm{T}$ cell receptor zeta chain through phosphotyrosine-Src homology domain-2 interactions. J Cell Biol 145: 377-89

VORONINA S, LONGBOTTOM R, SUTTON R, PETERSEN OH, TEPIKIN A (2002) Bile acids induce calcium signals in mouse pancreatic acinar cells: implications for bile-induced pancreatic pathology. J Physiol 540: 49-55

WAJANT H (2002) The Fas signaling pathway: more than a paradigm. Science 296: $1635-6$

WANG NS, UNKILA MT, REINEKS EZ, DISTELHORST CW (2001) Transient expression of wild-type or mitochondrially-targeted Bcl-2 induces apoptosis, whereas transient expression of endoplasmic reticulumtargeted Bcl-2 is protective against Bax-induced cell death. J Biol Chem 276: 44117-28

WANG Y, PENNOCK SD, CHEN X, KAZLAUSKAS A, WANG Z (2004) Platelet-derived growth factor receptor-mediated signal transduction from endosomes. J Biol Chem 279: 8038-46

WEIJZEN S, ZLOBIN A, BRAID M, MIELE L, KAST WM (2003) HPV16 E6 and E7 oncoproteins regulate Notch-1 expression and cooperate to induce transformation. J Cell Physiol 194: 356-62

WHEELOCK MJ, JOHNSON KR (2003a) Cadherins as modulators of cellular phenotype. Annu Rev Cell Dev Biol 19: 207-35

WHEELOCK MJ, JOHNSON KR (2003b) Cadherinmediated cellular signaling. Curr Opin Cell Biol 15: 509-14

WIENTJES FB, SEGAL AW (2003) PX domain takes shape. Curr Opin Hematol 10: 2-7

WILLERT K, BROWN JD, DANENBERG E, DUNCAN AW, WEISSMAN IL, REYA T, YATES JR, 3RD, NUSSE R (2003) Wnt proteins are lipid-modified and can act as stem cell growth factors. Nature 423: 448-52

WILLIAMSON P, CHRISTIE A, KOHLIN T, SCHLEGEL RA, COMFURIUS P, HARMSMA M, ZWAAL RF, BEVERS EM (2001) Phospholipid scramblase activation pathways in lymphocytes. Biochemistry 40 : 8065-72

YOKOYAMA S, TACHIBANA K, NAKANISHI $\mathrm{H}$, YAMAMOTO Y, IRIE K, MANDAI K, NAGAFUCHI A, MONDEN M, TAKAI Y (2001) Alpha-cateninindependent recruitment of ZO-1 to nectin-based cell-cell adhesion sites through afadin. Mol Biol Cell 12: 1595-609

YU A, BYERS DM, RIDGWAY ND, MCMASTER CR, COOK HW (2000) Preferential externalization of newly-synthesized phosphatidylserine in apoptotic U937 cells is dependent on caspase-mediated pathways. Biochim Biophys Acta 1487: 296-308 
YU A, MCMASTER CR, BYERS DM, RIDGWAY ND, COOK HW (2003) Stimulation of phosphatidylserine biosynthesis and facilitation of UV-induced apoptosis in Chinese hamster ovary cells overexpressing phospholipid scramblase 1. J Biol Chem 278: 9706-14

ZARU R, CAMERON TO, STERN LJ, MULLER S, VALITUTTI S (2002) Cutting edge: TCR engagement and triggering in the absence of large-scale molecular segregation at the T cell-APC contact site. J Immunol 168: 4287-91

ZHANG W, SLOAN-LANCASTER J, KITCHEN J, TRIBLE RP, SAMELSON LE (1998a) LAT: the ZAP-
70 tyrosine kinase substrate that links $\mathrm{T}$ cell receptor to cellular activation. Cell 92: 83-92

ZHANG W, TRIBLE RP, SAMELSON LE (1998b) LAT palmitoylation: its essential role in membrane microdomain targeting and tyrosine phosphorylation during $\mathrm{T}$ cell activation. Immunity 9: 239-46

ZHANG W, SOMMERS CL, BURSHTYN DN, STEBBINS CC, DEJARNETTE JB, TRIBLE RP, GRINBERG A, TSAY HC, JACOBS HM, KESSLER CM, LONG EO, LOVE PE, SAMELSON LE (1999) Essential role of LAT in $\mathrm{T}$ cell development. Immunity 10: 323-32 